DOI 10.35381/cm.v7i1.535

\title{
La aplicación de los principios procesales en el desarrollo de las audiencias virtuales
}

The application of procedural principles in the development of virtual hearings

\author{
Alex Enrique Yun-Hon-Sacoto \\ dq.alexeyh30@uniandes.edu.ec \\ Universidad Regional Autónoma de los Andes, Quevedo \\ Ecuador \\ https://orcid.org/0000-0002-4867-3250 \\ César Elías Paucar-Paucar \\ uq.cesarpaucar@uniandes.edu.ec \\ Universidad Regional Autónoma de los Andes, Quevedo \\ Ecuador \\ https://orcid.org/0000-0003-2624-0427 \\ Pamilys Milagros Moreno-Arvelo \\ uq.pamilysmoreno@uniandes.edu.ec \\ Universidad Regional Autónoma de los Andes, Quevedo \\ Ecuador \\ https://orcid.org/0000-0001-8913-4352
}

Recibido: 01 de mayo de 2021

Aprobado: 01 de agosto de 2021 


\section{Estimado Editor (a):}

La Corte Nacional de Justicia, establece que los sistemas informáticos, deben desarrollarse con la finalidad de brindar un servicio ágil y expedito, para quienes tengan la necesidad de acceder a la administración de justicia, debiendo desarrollar de manera obligatoria efectividad y resultados positivos, desarrollando así una herramienta que permita una gestión de los procedimientos que satisfagan las necesidades y expectativas de los ciudadanos en la cual se debe asegurar un acceso óptimo e integral a la información y a una comunicación fluida entre las partes procesales. (Corte Nacional de Justicia, 2021)

A raíz de la expansión de la pandemia mundial, el gobierno de Ecuador promulga medidas de aislamiento y distanciamiento social, suspendiendo los servicios propios de la función judicial, en lo referente al acceso físico de las personas a las instalaciones de la función judicial a nivel nacional, determinando todas estas precauciones dentro del denominado protocolo de bioseguridad para la normalización de actividades de la función judicial durante la pandemia mundial.

En este sentido, el 16 de marzo de 2020, el presidente constitucional de la república ecuatoriana, a través de decreto ejecutivo No. 1710 establece estado de excepción por calamidad pública en todo el Estado por sesenta días siendo este renovado por treinta días más el día 15 de mayo del 2020.

Así mismo, la expansión universal de la crisis sanitaria Covid-19 desencadeno dentro del territorio ecuatoriano una desorganización nunca antes vista en el sistema de justicia del Estado, en el cual se desarrollaron carencias extremas en las líneas de comunicación por parte del consejo de la judicatura hacia todas las dependencias judiciales a nivel nacional y público en general en lo referente a como funcionaria la justicia mientras durara la emergencia sanitaria. (Comisión Interamericana de Derechos Humanos, 2020).

Por ello, la Corte Nacional de Justicia, como representante del órgano máximo de administración de justicia de carácter ordinario dentro del territorio ecuatoriano, desarrolló un protocolo de audiencias virtuales en la institución, teniendo como 
objetivo primordial la garantía de la continuidad del sistema procesal, así como desarrollar su uso durante la pandemia para minimizar los peligros de contagio de Covid-19, evitando aglomeraciones dentro de las instituciones de la función judicial. (Corte Nacional de Justicia, 2021).

En esta primera etapa se desarrollaron numerosas resoluciones y reglamentos que fueron emitidos por parte del Conejo de la Judicatura que se contradecían entre sí, generando situaciones de incertidumbre e inseguridad, tanto en los usuarios como en los funcionarios públicos operadores de justicia en todos sus niveles. Así mismo en esta primera instancia de la crisis sanitaria, tal era el grado de desorganización que incluso se sugirió la supresión de la tramitación de acciones de tutela efectiva de derechos humanos a nivel constitucional por parte del Consejo de la Judicatura, hecho que en vista de su gravedad fue alertada y resuelta por la Corte Constitucional del Ecuador, la cual le recordó a este órgano la obligación del sistema de justicia de garantizar todos los mecanismos existentes y posibles de tutela de derechos humanos. (Comisión Interamericana de Derechos Humanos, 2020). Con base en lo expuesto, se desarrolla la idea de que a causa de la pandemia mundial Covid-19, el Ecuador asumió de manera urgente la modalidad virtual, desarrollando consigo una serie de vulneraciones o debilidades en lo correspondiente al correcto acceso a la justicia en el desarrollo de audiencias telemáticas, dando lugar a críticas de parte del gremio de profesionales del derecho en lo correspondiente a la vulneración de los principios del procedimiento penal a través de esta modalidad, a causa de un acceso limitado a la justicia para grupos vulnerables, la limitación de material tecnológico en la función judicial para el desarrollo de audiencias, o la falta de difusión de información sobre el funcionamiento de esta modalidad a la población. Sin embargo, Arévalo Morales, Bautista Cruz y Gómez Pérez (2019) plantean que:

Ahora con la modalidad de las Audiencias Virtuales los acusados no necesitan ser trasladados fuera del recinto carcelario, haciendo el uso de internet, pantallas LED y cámaras en la cual la interacción desde el recinto penal y el despacho del juez se marca de una manera fluida como si fuese una audiencia presencial, pero que principios se debe tomar en cuenta que se pueden vulnerar. (p. 6). 
En consecuencia, se dispuso a retomar actividades de manera parcial en actividades jurisdiccionales en las dependencias judiciales nacionales, para que se pudieran tramitar de manera preferencial procesos judiciales que se encontraban en tramitación antes de la explosión de la pandemia mundial tanto de manera oral como de manera escrita. También se determinó que la Corte Nacional de Justicia en base a las atribuciones que la ley y la constitución le atribuía, emitiría un documento de guía procesal para que la función judicial aplicara el sistema de justicia ecuatoriano a través de medios telemáticos y virtuales que garantizaran los derechos al debido proceso. De acuerdo a las normas vigente mediante la carta fundamental del Estado ecuatoriano en su articulado 169 se establece que el sistema procesal del Ecuador desarrolla la finalidad principal de ejercer justicia, estableciendo que todas las normas procesales que conforman el ordenamiento jurídico ecuatoriano se rigen a través de principios fundamentales entre los cuales se incluyen la inmediación, eficacia de la justicia, simplificación de los procedimientos, uniformidad y economía procesal, y que a través de estos se tiene la obligación de asegurar el derecho al debido proceso. (Constitución de la República del Ecuador, 2008).

En el siguiente cuadro se muestra las normas que apoyan la ejecución del apoyo en el uso de telemático.

\section{Cuadro 1.}

Audiencia telemática.

\begin{tabular}{|l|l|}
\hline \multicolumn{1}{|c|}{ Norma constitucional } & \multicolumn{1}{|c|}{ Mandato } \\
\hline $\begin{array}{l}\text { Constitución de la República del Ecuador } \\
(2008)\end{array}$ & $\begin{array}{l}\text { Artículo. 75.-Toda persona tiene derecho al } \\
\text { acceso gratuito a la justicia y a la tutela } \\
\text { efectiva, imparcial y expedita de sus } \\
\text { derechos e intereses, con sujeción a los } \\
\text { principios de inmediación y celeridad; en } \\
\text { ningún caso quedará en indefensión. El } \\
\text { incumplimiento de las resoluciones } \\
\text { judiciales será sancionado por la ley. }\end{array}$ \\
\hline Código Orgánico Integral Penal (2014) & $\begin{array}{l}\text { Artículo 565.- Audiencias telemáticas u otros } \\
\text { medios similares. - Cuando por razones de } \\
\text { cooperación internacional, seguridad o } \\
\text { utilidad procesal y en aquellos casos en que }\end{array}$ \\
\hline
\end{tabular}




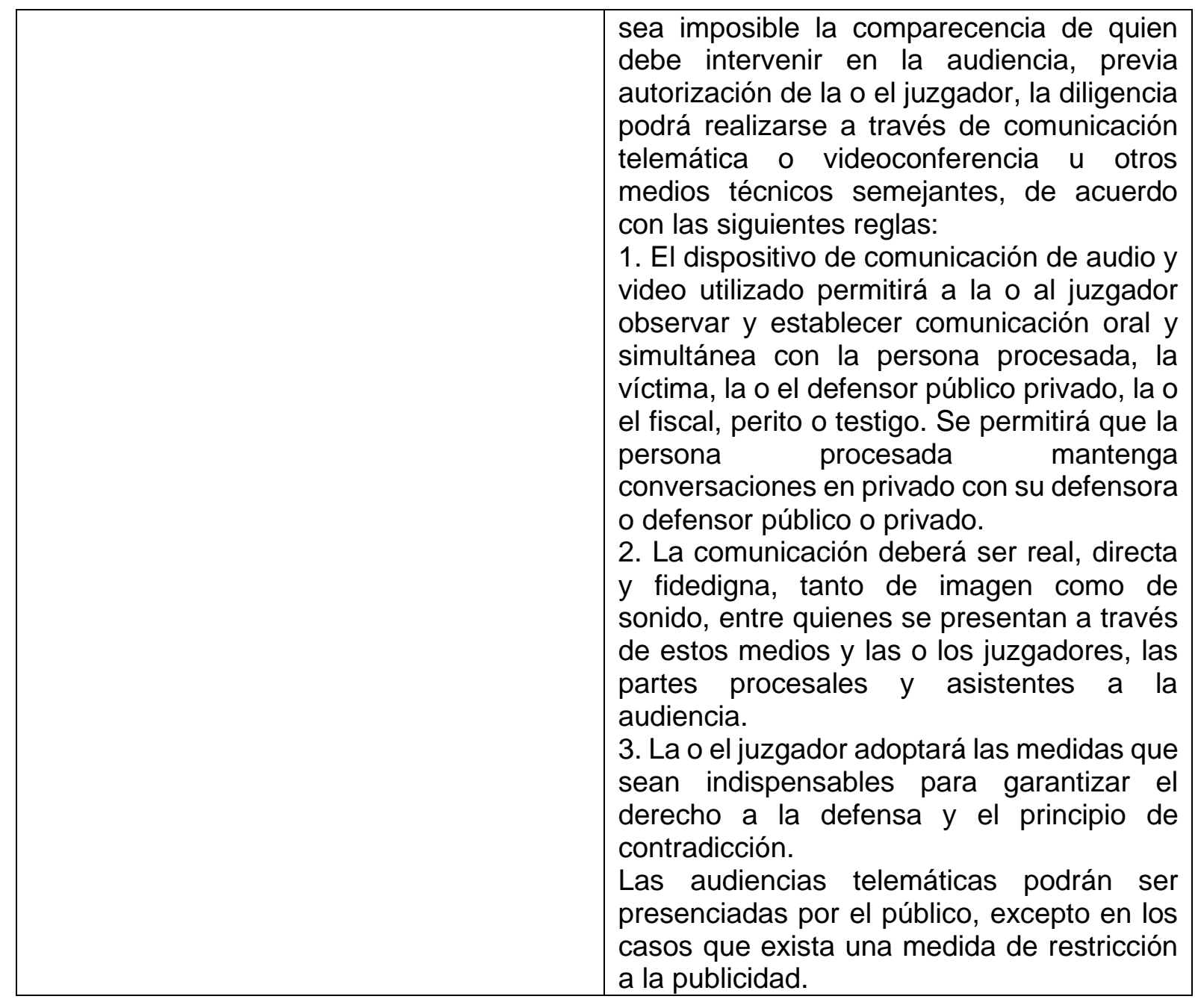

Elaboración: Los autores.

En base a estas apreciaciones acerca de los medios telemáticos y las audiencias de juicio, cabe destacar, que a causa de la pandemia mundial, el Ecuador se adapto al desarrollo de la funcion judicial via telemática, generando vulneraciones en el acceso a la justicia, para mienbros de la sociedad de escasos recursos o que desconocen la utilizacion de medios tecnológicos debido a las brechas que existen en nuestra sociedad con respecto al uso de la tecnología, o las diferentes falencias desarrolladas a la hora del avance de esta modalidad procesal, al existir desconocimiento de la utilización de los sistemas que permiten el desarrollo de audiencias virtuales o falta de 
información sobre los mismo en la sociedad, limitando de esta manera su acceso a la justicia, y por ende atentando contra los derechos al debido proceso de las personas. Se concluye que, el desarrollo de audiencias a través de sistemas informáticos están previstas por la legislación ecuatoriana, y desarrolladas en una mayor medida por lineamientos y protocolos emitidos en medio de la pandemia Covid-19, esta herramienta jurídica debe desarrollarse con mayor profundidad, pues su presencia es superficial dentro de la legislación ecuatoriana, y para asegurar que no se vulneren principios como el debido proceso, el acceso a la justicia, la inmediación o la publicidad, se deben desarrollar estructuras completas que permitan a la justicia ofrecer un proceso completo e integral de la defensa de derechos e intereses de las personas.

\section{FINANCIAMIENTO}

No monetario.

\section{AGRADECIMIENTO}

A la Universidad Regional Autónoma de los Andes, Quevedo Ecuador, por motivar el desarrollo de la Investigación.

\section{REFERENCIAS}

Arévalo Morales, Y., Bautista Cruz, H. y Gómez Pérez, V. (2019) La flexibilización del principio de inmediación con la realización de audiencias virtuales en el proceso penal. Trabajo de Grado para obtener el título de Licenciado(A) en Ciencias Jurídicas. Universidad de El Salvador. Recuperado de: https://n9.cl/dafoe

Asamblea Nacional Constituyente de la República del Ecuador, (2008). Constitución de la República del Ecuador. Montecristi. Registro Oficial 449 de 20-oct-2008. Recuperado de https://n9.cl/sia

Asamblea Nacional (2014). Código Orgánico Integral Penal. Registro Oficial № 180. Recuperado de https://url2.cl/53c6h 
Comisión Interamericana de Derechos Humanos (2020) Informe de audiencia Funcionamiento de la justicia en la pandemia por Covid 19" Audiencia celebrada el 09 de octubre de 2020. 177 Período de sesiones. Recuperado de: https://n9.cl/3e14

Corte Nacional de Justicia (2021) Protocolo para la realización de audiencias telemáticas en la Corte Nacional de Justicia. Recuperado de: https://n9.cl/zzeqd

Presidencia de la República de Ecuador. (2020). Decreto presidencial № 1017. Recuperdo de: https://n9.cl/f3kkd 